\title{
Investigations on the Influence of the Addition of Carbon Dioxide on the Production and Properties of Rapidly Set Wood-Cement Composites
}

\author{
M. H. Simatupang, ${ }^{*}$ C. Habighorst, H. Lange \& A. Neubauer
}

Federal Research Center for Forestry and Forest Products, Institute of Wood Chemistry and Chemical Technology of Wood, D-2050 Hamburg, Germany

(Received 30 May 1994; accepted 13 February 1995)

\section{Abstract}

This paper gives a short description of the manufacturing process of cement particle boards. Production methods currently used are characterized by a pressing time of boards of about $8 \mathrm{~h}$. Also, flakes from only a limited number of wood species are suitable as reinforcing material. A new process is described where pressing time is reduced to only $4 \mathrm{~min}$, and which allows the utilization of wood species not known as suitable so far. This process is distinguished by the injection of carbon dioxide into the furnish during pressing, whereupon the cement sets within a few minutes. A similar process, also described in this paper, uses carbonates of ammonium, sodium or potassium as additives to the mixture of wood flakes, cement and water. The carbonates decompose during pressing and carbon dioxide is released to react with calcium hydroxide from the hydration process. Thus, the cement sets within a very short time. The paper compares the properties of cement particle boards made according to these new processes with those from the old process.

Keywords: Wood fibre-cement composites, particle boards, manufacture, production time, setting time, density, bending strength, composite materials.

\section{INTRODUCTION}

A schematic view of the industrial process of cement particle board production according to

\footnotetext{
* Present address: School of Industrial Technology, Uni-
} versity of Sains Malaysia, 11800 Penang, Malaysia.
Elmendorf ${ }^{1}$ is given in Fig. 1. Appropriate wood particles are soaked with gauge water which may contain cement setting accelerators. Portland cement is then added, and blending is continued until a homogeneous mixture is obtained. A water/binder ratio of about 0.4 yields a spreadable mixture of wood particles, water and cement (the furnish). Thus, equipments commonly used for the manufacture of particle boards are suitable for the production of cement-bonded boards.

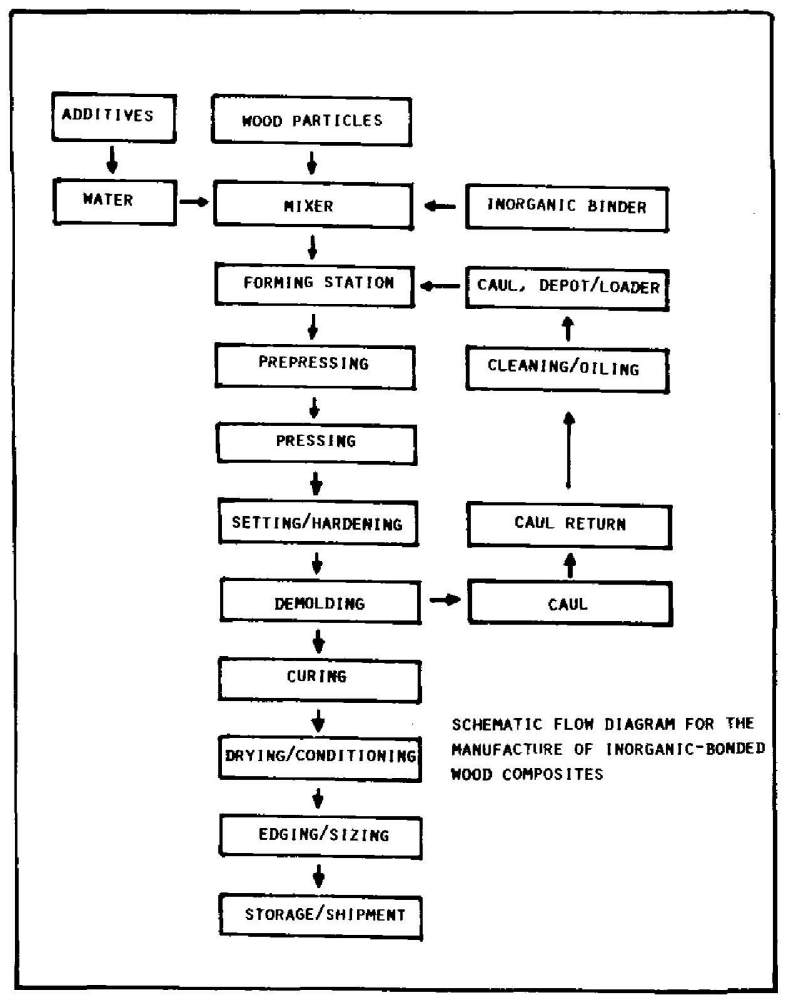

Fig. 1. Schematic flow diagram for the manufacture of cement particle boards. 
The molding of boards begins with felting the furnish continuously on a moving belt or a steel caul to form a mat. The furnish may then be compressed by either a discontinuous or a continuous press. Presently, only discontinuous pressing equipment is in use. Individual mats are formed by a cutting device, whereupon the cauls with the furnish are stacked on heavy steel bottom plates placed on a lorry. When a predetermined height is reached, a final heavy steel plate is put on top of the pile. The lorry is moved into the hydraulic press and the mats are stack-pressed to yield boards of preadjusted thickness. Under pressure, water is squeezed out of the wood particles and combines with the cement to form a paste. A pressure of 1.5-3.0 $\mathrm{MPa}$ is required to obtain coherent boards.

Usually an accelerator is added, e.g. calcium chloride, aluminium sulfate with or without waterglass. While stack-pressed, the boards are heated up to $80^{\circ} \mathrm{C}$. This helps to shorten the time required for the composite to gain sufficient internal bonding strength to compensate the spring-back forces of the wood particles. Nevertheless, a minimum stack-press time of $8 \mathrm{~h}$ is required. To reduce this time, two modifications of the Elmendorf process are presently used. For the first modification, a rapid hardening cement is used. This cement consists of a mixture of alumina cement, portland cement, $\beta$-gypsum hemihydrate, lime and an organic carbonate. Ettringite, formed in great amounts during setting, causes the fast solidification of the inorganic binder. In the subsequent hardening period tobermorite will be formed. The press time of cement particle boards can be reduced to between 10 and $16 \mathrm{~min}$ at $70-90^{\circ} \mathrm{C} .^{2}$ For the second modification, gaseous carbon dioxide is injected into the cement particle boards during pressing. The press time is only $4 \mathrm{~min}$ and the boards are subsequently cured for two weeks at ambient temperature for further hardening. ${ }^{3}$ In both processes, woody materials, which were previously classified as unsuitable for the production of cement particle boards before, may be used.

The carbonation process is the subject of this paper. Properties of specimens fabricated according to conventional methods and by injection of carbon dioxide are compared. Carbon dioxide may also be emitted in situ from the degradation of carbonates of ammonium, potassium or sodium. The suitability of such salts for a reduction of the setting time of cement pastes is also investigated.

\section{MATERIALS AND METHODS}

\subsection{Investigation of cement setting (solidification)}

Two methods were applied to trace the early hardening of cement and to determine the setting time. In these approaches, the electrical conductivity and the temperature during setting, respectively, were recorded continuously. By the first method, the setting time is defined as the inflexion point of the final part of a conductivity vs time curve, whereas in the second method the setting time is given by the maximum temperature in a temperature vs time curve. The corresponding time and temperature are designated as total hydration time and as maximum hydration temperature, respectively.

The electrical conductivity method was used to trace the setting of neat cement paste under the influence of various carbon dioxide pressures. The maximum temperature method was applied to examine the influence of potassium carbonate on the setting of neat cement with and without addition of waterglass at various temperatures. These two experimental series were conducted using small samples of cement paste and cement-wood specimens, respectively. For an additional observation of processes during the setting of experimental cement particle boards, only the maximum temperature method was used.

\subsection{Injection of carbon dioxide}

The apparatus used to study the solidification of neat cement paste is shown schematically in Fig. 2. It consists of a pressure vessel connected to a carbon dioxide source and a vacuum pump. A modified spark plug (type Super RO 642, Bosch $\mathrm{GmbH}$ ) served as an electrode. The central electrode was reduced to a width of $2.5 \mathrm{~mm}$ and a thickness of $0.8 \mathrm{~mm}$. The thickness of the side electrode was also reduced to $0.8 \mathrm{~mm}$ to match that of the central one. Hence, the available space between the two electrodes was only $2.5 \mathrm{~mm}$ wide and $0.8 \mathrm{~mm}$ thick. One centimeter of the thread was removed from the lower end of the spark plug. Two opposite holes (diameter $2 \mathrm{~mm}$ ) were drilled into the thread-free part of the modified spark plug to allow rapid removal 


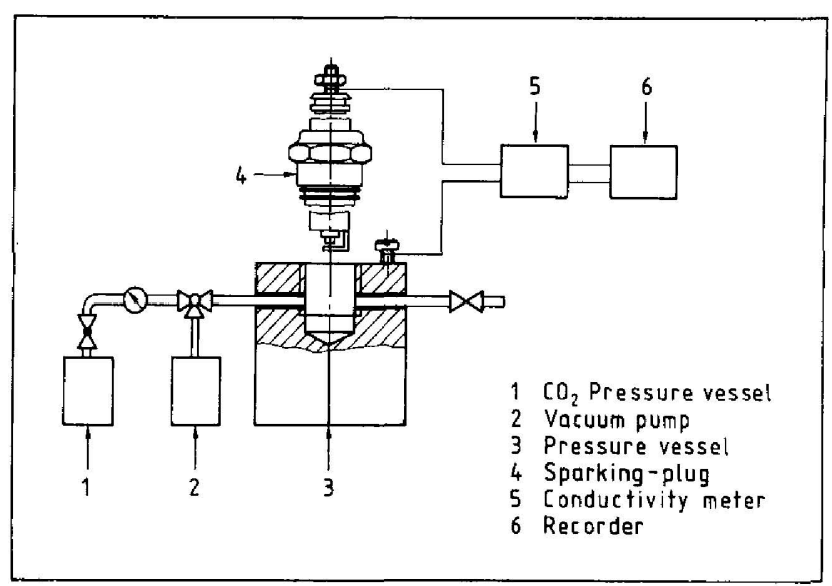

Fig. 2. Schematic of apparatus to monitor the setting of cement paste by measuring the electrical conductivity at various carbon dioxide pressures.

of air and moisture. A Phillips (Type PW 9505) electrical conductivity apparatus was applied in combination with a Metrawatt (Type Servogor 310) recorder. Vacuum was generated by a regulated water-jet pump. The neat cement paste was prepared by mixing $1 \mathrm{~g}$ of portland cement with $0.35 \mathrm{~cm}^{3}$ of distilled water. Cement paste was applied with a micro-spatula between the central and the side eletrode. A vacuum of 0.1 bar was applied after screwing the spark plug into the pressure vessel. The electrical conductivity of the paste decreased due to the evaporation of moisture. Carbon dioxide was introduced after the relative electrical conductivity dropped to $30 \%$. Carbon dioxide pressure was applied in steps from 3 to 9 bar.

For the manufacture of wood/cement specimens a specially designed device was used which is schematically shown in Fig. 3. It is made of stainless steel and consists of three parts: the lower part with a perforated disc and a three way valve to apply either vacuum or carbon dioxide pressure (No. 4 in Fig. 3); the press sleeve to take up the moist wood/cement mixture (No. 3 in Fig. 3) and the piston to compress the furnish (No. 1 in Fig. 3). The temperature in the specimen was measured by a thermocouple (No. 2 in Fig. 3) connected to a recorder. Wood particles $(>1 \mathrm{~mm}$ and $<2$ $\mathrm{mm}$ ) were soaked with distilled water and blended with cement. Mixing was accomplished by use of a common kitchen blender. The furnish was then filled into the press sleeve and slightly pressed using the piston. The filled die, provided with the piston, was placed under a hydraulic press and compressed at $4 \mathrm{MPa}$. Carbon dioxide was introduced after application of

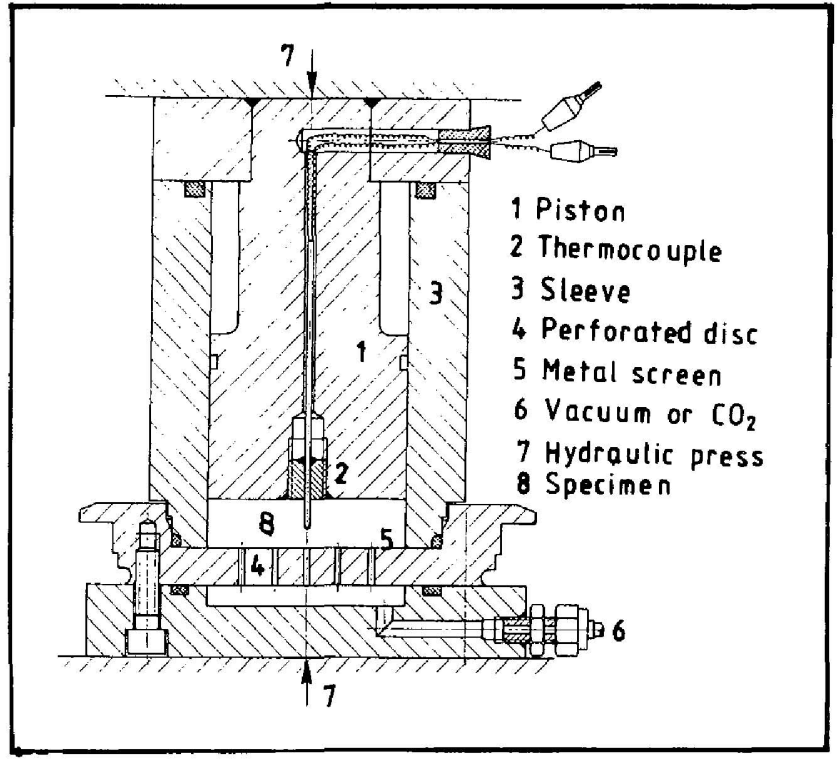

Fig. 3. Schematic of apparatus to fabricate wood/cement specimens.

a vacuum of $0 \cdot 1$ bar. The compressed specimens had a diameter of $50 \mathrm{~mm}$ and a target thickness of $12.4 \mathrm{~mm}$. The target density (oven dry) was set to be $1 \cdot 2$. For one specimen, $6 \cdot 3 \mathrm{~g}$ (oven dry) wood particles and $18.9 \mathrm{~g}$ portland cement were required, and the water/cement $(\mathrm{w} / \mathrm{c})$ ratio - calculated according to Simatupang ${ }^{4}$ — was varied from $0 \cdot 1$ to $0 \cdot 6$. This ratio takes into account that part of the absorbed moisture in the wood - the amount below the fiber saturation point - that is not accessible to the cement. For most of the wood species the fiber saturation point may be assumed as $30 \%$. With the moisture content of wood particles lower than the fiber saturation, additional water is required. ${ }^{4}$

Specimens fabricated according to conventional methods, i.e. without the injection of carbon dioxide, were left under pressure overnight, using the die shown in Fig. 3. Material requirements were the same as above, however, the water/cement ratio was constant at $0 \cdot 35$. For each set of variables at least four wood/cement specimens were produced and tested.

Experimental cement particle boards were produced using a press platen that allowed the injection of carbon dioxide during compression (Fig. 4). A heating element was used in the carbon dioxide supply line to prevent the gas from freezing. In most experiments, gas was introduced only from the upper platen, because similar results were found with gas introduction from either the upper or bottom platen or both upper and lower platens. 


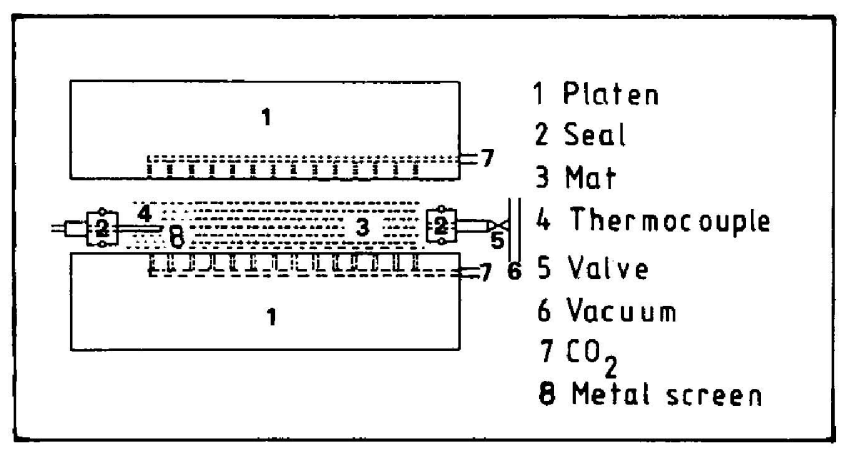

Fig. 4. Schematic of press platen with seal for carbon dioxide.

A metal screen was placed on the bottom platen and a seal was used to prevent undesired loss of carbon dioxide. For a good distribution of carbon dioxide, vacuum was applied previous to gas introduction. ${ }^{5}$ Vacuum application also had to precede the opening of the press in order to reduce the partial pressure, to remove vapor, and to avoid blows.

Three layer cement particle boards were fabricated from spruce and larch flakes. Flakes for the outer layers were retained on a $1 \mathrm{~mm}$ screen after passing $2 \mathrm{~mm}$, those for the inner layer passed a $6 \mathrm{~mm}$ screen and were retained on one of $4 \mathrm{~mm}$. The board measured $40 \times 40 \times 1.3 \mathrm{~cm}$-thick with a target density (oven dry) of $1 \cdot 2$. The weight ratio of both outer layers to the central layer was $1: 2 \cdot 3$. The ratio of cement to wood was $3: 1$ in the outer layers and 2.6:1 in the central layer. The w/c ratio was $0 \cdot 35$. Carbon dioxide in most cases was introduced at a pressure of 7 bar. In a limited number of experiments the pressure of carbon dioxide was varied from 1 to 9 bar. The fresh fabricated boards were stored for two weeks in a moist environment and then cut into specimens of $23 \times 5 \mathrm{~cm}$. These were conditioned for another two weeks in a climatized room at $20^{\circ} \mathrm{C}$ and $65 \% \mathrm{RH}$, and then tested. The moisture content of the specimens previous to testing was around $10 \%$. The determination of the properties was accomplished according to German Industrial Standard (DIN 52 362, 52 364 ). For each variable two boards were fabricated, and each board yielded eight specimens of $23 \times 5 \mathrm{~cm}$.

\subsection{Addition of carbonate}

To study the influence of various carbonates on cement solidification the apparatus shown schematically in Fig. 5 was used. Ten grams of cement was mixed with $4 \mathrm{~cm}^{3}$ of distilled water

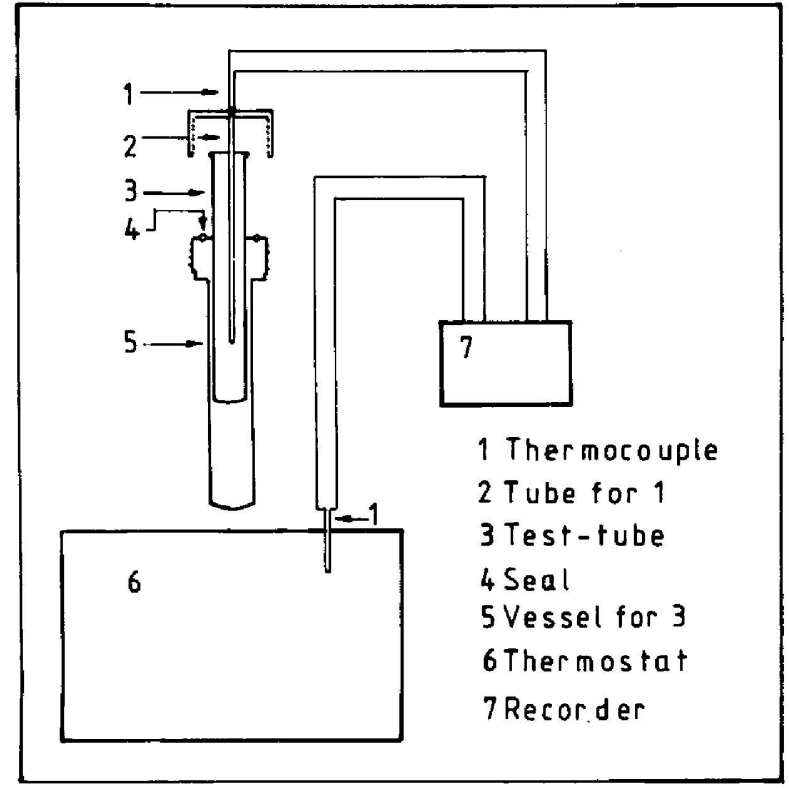

Fig. 5. Schematic of apparatus to monitor the setting of cement paste with various additives at various temperatures by measuring the hydration temperatures.

in a small test-tube. The gauge water could contain additives. Blending was accomplished with a test-tube mixer. The small pressure vessel containing the filled glass tube was placed in a thermostat. The temperature in the cement paste and that of the water bath were simultaneously measured with two thermocouples and registered by a two channel recorder. The temperature of the setting cement paste can exceed that of the water bath due to the exothermic reaction. After a while, the temperature drops to that of the water bath. When the temperature of the cement paste exceeds that of the water bath, the solidification, or setting, is considered to start - the initial setting - and when it has dropped to that of the water bath, the setting is ended. Measurements of the setting or solidification time start with the insertion of the test-tube into the thermostat and end when maximum temperature is indicated by the recorder.

Electrically heated press platens were used to form cement particle board. The flakes were identical to those used for the manufacture of cement particle boards under the influence of carbon dioxide injection described above. The carbonate was dissolved in water, resulting in a temperature increase. The solution was used as gauge water after attaining ambient temperature.

Waterglass, when used to extend the open time, was dissolved in the carbonate solution. A 
thermocouple and a recorder were used to measure the temperature in the board during pressing. The further handling and testing of the cement particle boards was the same as already described.

\subsection{Testing and analytical methods}

The compressed wood-cement specimens were stored in sealed plastic bags until drying and testing. Rapid drying was accomplished at a vacuum of 0.04 bar and at $50^{\circ} \mathrm{C}$. The moisture content dropped from about 28 to $10 \%$ within $1.5 \mathrm{~h}$. Some specimens were dried to constant weight at $105^{\circ} \mathrm{C}$ at atmospheric pressure to prevent further hydration. The dried specimens were ground and then stored over silica gel and potassium hydroxide in a dessicator until they were used for analysis.

Calcium hydroxide was determined by extraction of the dried and ground specimen with isopropyl alcohol followed by titration with hydrochloric acid. $^{6}$ Calcium carbonate was determined by treating the dried and ground sample with diluted hydrochloric acid and measuring the released amount of carbon dioxide volumetrically according to German Industrial Standard (DIN 1060 Part 2). A small reaction tube of $25 \mathrm{~cm}^{3}$ was used and the volume of carbon dioxide was measured with an Orsat apparatus. For each determination, $0.5 \mathrm{~g}$ of the ground material was required.

\section{RESULTS}

\subsection{Injection of carbon dioxide}

\subsubsection{Neat cement paste}

A typical curve of conductivity change with time at a carbon dioxide pressure of 7 bar is shown in Fig. 6. As soon as carbon dioxide is introduced, the cement paste at the surfaces carbonates rapidly along with a sharp decrease in electrical conductivity. Carbon dioxide pressure does not show any influence on this initial reaction. The electrical conductivity stops falling and increases slightly again, probably resulting from the formation of unstable hydrogen carbonate. Carbon dioxide then diffuses into the cement paste and the electrical conductivity decreases steadily to reach a constant value. The inflexion point in the final part of the curve is considered to be the setting time, or solidification time, of the cement paste. With

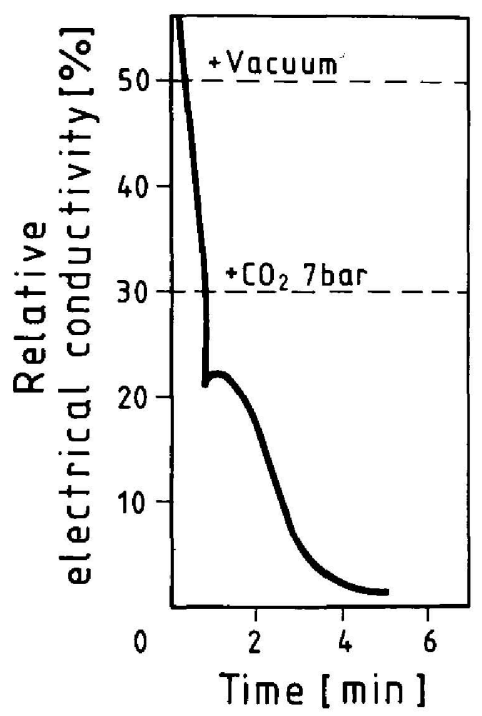

Fig. 6. Electrical conductivity of cement paste at a carbon dioxide pressure of 7 bar.

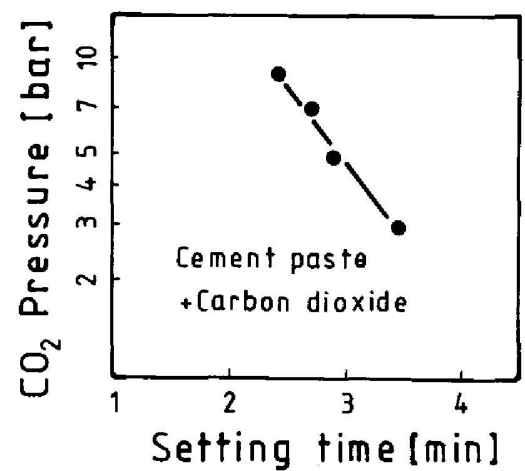

Fig. 7. Influence of carbon dioxide pressure on the setting rate of cement paste.

increasing carbon dioxide pressure, the carbonation, or setting time, decreases (Fig. 7).

\subsubsection{Wood/cement specimens}

A typical temperature curve of solidification under influence of carbon dioxide is shown in Fig. 8. The course of solidification is not in full accordance with that observed by the above described spark plug method using cement pastes. It was already shown that the spark plug method features a sharp decrease of conductivity immediately upon introduction of carbon dioxide. However, when wood/cement samples were brought to set under pressure, the initial reaction was not observed earlier than from $30 \mathrm{~s}$ to $1 \mathrm{~min}$ after gas injection. If, however, calcium hydroxide was added to the cement, or if the furnish was allowed to stand for half an hour previous to compression, the temperature also increased immediately after introducing carbon 
dioxide. Thus, in the basic configuration of Method 2, calcium hydroxide is not available in sufficient amounts at the moment of gas injection. In wood/cement specimens the absorbed water has first to be squeezed from the wood particles to combine with the inorganic binder. A small portion of the clinker phase hydrates and calcium hydroxide is released, which is then carbonated. However, if the furnish is pressed

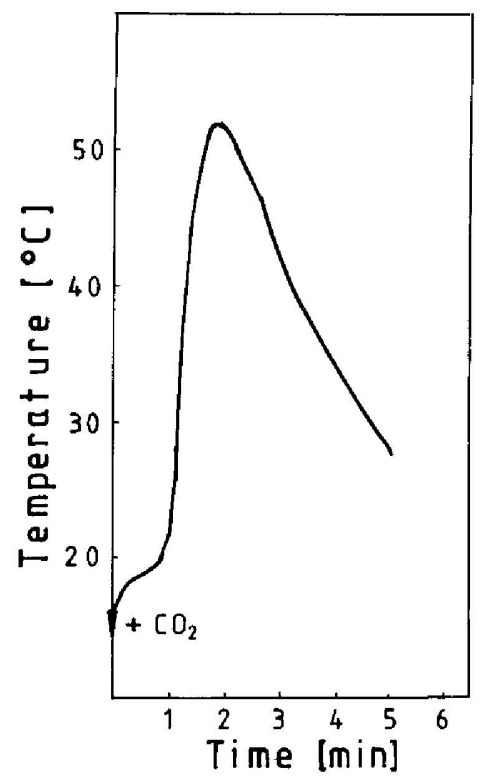

Fig. 8. Hydration temperature of wood/cement specimen at a carbon dioxide pressure of 7 bar and a w/c ratio of $0 \cdot 35$. only some time after blending, moisture from the wood particles would diffuse and react with the cement. In this case, calcium hydroxide is already available at the onset of pressing and is directly carbonated. The same effect is observed if additional calcium hydroxide is blended into the cement previous to the preparation of the furnish.

A similar pattern of temperature development was also observed during pressing of experimental cement particle boards.

\subsubsection{Influence of carbon dioxide pressure.} Increasing the gas pressure will result in higher maximum hydration temperatures and shorter setting times, and the calcium carbonate content of the specimens, determined as carbon dioxide, increases (Table 1). Since the improvements achieved by an increase of pressure from 7 to 9 bar are not significant, 7 bar was taken as a standard for all further experiments.

\subsubsection{Influence of water/cement ratio. The} water/cement ratio has an influence on the maximum hydration temperature, the total hydration time, the weight increase and the calcium carbonate content of the specimens. The highest maximum hydration temperature, weight increase and calcium carbonate content are shown in Table 2 for specimens which are

Table 1. Influence of $\mathrm{CO}_{2}$ pressure on maximum hydration temperature, total hydration time and $\mathrm{CaCO}_{3} \mathrm{content}$ of wood/cement specimens

\begin{tabular}{cccc}
\hline $\begin{array}{c}\mathrm{CO}_{2} \text { pressure } \\
\text { (bar) }\end{array}$ & $\begin{array}{c}\text { Maximum hydration } \\
\text { temperature } \\
\left({ }^{\circ} \mathrm{C}\right)\end{array}$ & $\begin{array}{c}\text { Total hydration } \\
\text { time } \\
(\mathrm{s})\end{array}$ & $\begin{array}{c}\text { CaCO} \mathrm{O}_{3} \text { content } \\
(\%)\end{array}$ \\
\hline 5 & 50 & 115 & $27 \cdot 63$ \\
7 & 52 & 108 & $30 \cdot 59$ \\
9 & 54 & 93 & $31 \cdot 22$ \\
\hline
\end{tabular}

$\mathrm{CaCO}_{3}$ content of cement (PKZ 35F) $17 \cdot 21 \%$.

Table 2. Influence of water/cement (w/c) ratio on maximum hydration temperature, total hydration time, weight increase, $\mathrm{Ca}(\mathrm{OH})_{2}$ and $\mathrm{CaCO}_{3}$ content of wood/cement specimens

\begin{tabular}{|c|c|c|c|c|c|}
\hline \multirow[t]{2}{*}{$W / C$ ratio } & \multirow{2}{*}{$\begin{array}{c}\text { Maximum hydration } \\
\text { temperature } \\
\left({ }^{\circ} \mathrm{C}\right)\end{array}$} & \multirow{2}{*}{$\begin{array}{c}\text { Total hydration } \\
\text { time } \\
(s)\end{array}$} & \multicolumn{2}{|c|}{ Weight increase } & \multirow{2}{*}{$\begin{array}{c}\mathrm{CaCO}_{3} \text { content } \\
(\%)^{4}\end{array}$} \\
\hline & & & (g) & $(\%)^{\dagger}$ & \\
\hline $0 \cdot 1$ & 78 & 58 & $1 \cdot 58$ & $8 \cdot 36$ & $23 \cdot 29$ \\
\hline $0 \cdot 2$ & 87 & 54 & $2 \cdot 35$ & $12 \cdot 43$ & $28 \cdot 08$ \\
\hline $0 \cdot 3$ & 75 & 86 & $2 \cdot 64$ & $13 \cdot 97$ & $29 \cdot 83$ \\
\hline $0 \cdot 4$ & 57 & 102 & $2 \cdot 42$ & $12 \cdot 80$ & $27 \cdot 08$ \\
\hline $0 \cdot 5$ & 49 & 125 & $2 \cdot 10$ & $11 \cdot 11$ & $25 \cdot 08$ \\
\hline $0 \cdot 6$ & 44 & 168 & 1.93 & $10 \cdot 21$ & $24 \cdot 70$ \\
\hline
\end{tabular}

${ }^{\dagger}$ Based on cement. Specimen contains $18.9 \mathrm{~g}$ cement (PKZ 35F) and $6.3 \mathrm{~g}$ wood particles (oven dry). $\mathrm{CaCO}_{3}$ content of PKZ $35 F=17 \cdot 21 \%$. 
Table 3. Influence of fabrication method on $\mathrm{Ca}(\mathrm{OH})_{2}$ and $\mathrm{CaCO}_{3}$ content, weight increase and surface soundness of wood/cement specimens

\begin{tabular}{|c|c|c|c|c|c|}
\hline $\begin{array}{l}\text { Fabrication } \\
\text { method }\end{array}$ & $\begin{array}{c}\mathrm{Ca}(\mathrm{OH})_{2} \text { content } \\
(\%)\end{array}$ & $\begin{array}{c}\mathrm{CaCO}_{3} \text { content } \\
(\%)\end{array}$ & \multicolumn{2}{|c|}{ Weight increase } & $\begin{array}{l}\text { Surface soundness } \\
(\mathrm{MPa})\end{array}$ \\
\hline \multicolumn{6}{|c|}{ Injection of carbon dioxide } \\
\hline $12 \mathrm{~h}$ & $0 \cdot 15$ & $33 \cdot 45$ & $2 \cdot 52$ & $13 \cdot 3$ & $0 \cdot 33$ \\
\hline 28 days & $0 \cdot 15$ & $33 \cdot 50$ & $2 \cdot 89$ & $15 \cdot 3$ & 0.43 \\
\hline \multicolumn{6}{|l|}{ Conventional } \\
\hline $12 \mathrm{~h}$ & $2 \cdot 18$ & $12 \cdot 51$ & 1.50 & 7.9 & ND \\
\hline 28 days & $4 \cdot 54$ & $12 \cdot 28$ & $2 \cdot 0$ & $10 \cdot 6$ & ND \\
\hline
\end{tabular}

${ }^{+}$Based on cement. $\mathrm{ND}=$ not determined. $\mathrm{CaCO}_{3}$ content of cement $(\mathrm{PKZ} 35 \mathrm{~F}) 17 \cdot 21 \%$.

made at a w/c ratio of $0 \cdot 3$. A decisive influence on the carbonation reactions has also been attributed to the availability of water and the porosity of the compressed furnish. The w/c ratio should be high enough to provide suffiI cient water, but at too high ratios the gas permeability is too low to ensure good penetration and carbonation.

The calcium hydroxide contents of specimens made by carbonation of wood/cement mixtures are remarkably low (Table 3). Unexpectedly, only minor weight increases of both types of specimen, made by conventional and by carbonation methods, were observed.

The X-ray diffraction of wood/cement specimens made by the conventional method (Fig. 9, curve 2, age $5 \mathrm{~h}$ and Fig. 9, curve 3, age 28 days) shows the presence of calcium hydroxide which is in agreement with the results of chemical analysis (Table 3). The amount of tricalcium silicate $\left(\mathrm{C}_{3} \mathrm{~S}\right)$ and of dicalcium silicate $\left(\mathrm{C}_{2} \mathrm{~S}\right)$ decreases with time $-5 \mathrm{~h}$ vs 28 days - whereas the amount of calcium hydroxide increases. The X-ray diffraction of specimens fabricated using carbon dioxide injection (Fig. 9, curve 4, age 5 h and Fig. 9, curve 5, age 28 days) does not show any calcium hydroxide. However, calcite is detected in rather high amounts. Compared to the X-ray diffraction of portland cement (Fig. 9, curve 1), all four specimens (Fig. 9, curves 2-5) show reduced amounts of $\mathrm{C}_{3} \mathrm{~S}$ and $\mathrm{C}_{2} \mathrm{~S}$. According to these results, both clinker phases take part in hydration and produce calcium hydroxide. In specimens made by conventional methods this calcium hydroxide is present as crystals, whereas in specimens produced by carbon dioxide injection it is carbonated into calcite.

\subsection{Addition of carbonates}

Added carbonates decompose during board pressing and the emitted carbon dioxide reacts

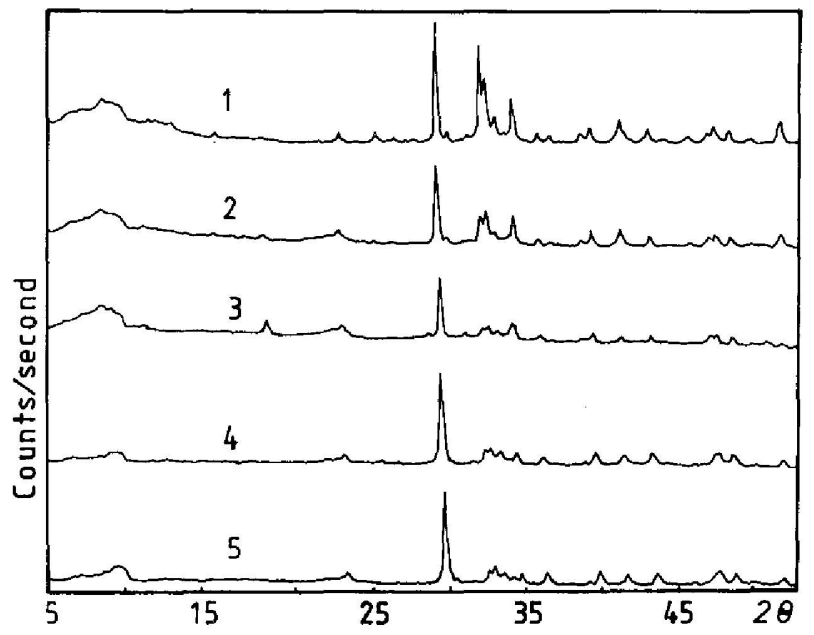

Fig. 9. X-ray diffraction of: $1=$ cement PKZ 35F; $2=$ wood/cement specimen made by conventional methods, age $5 \mathrm{~h}$; and $3=$ age 28 days. Specimen made by $\mathrm{CO}_{2}$ injection, age $5 \mathrm{~h}$.

with calcium hydroxide released by the cement paste to form a carbonate again. This makes the paste solidify rapidly. After compression of cement particle boards, the early bonds created by the set cement between the aggregates should be strong enough to counteract the spring-back forces of the wood particles. The early bending strength of such a board should be between 4 and $5 \mathrm{MPa}$.

This can be achieved by an addition of at least $7.5 \%$ of carbonate, based on cement. Such an amount of ammonium or sodium carbonate causes the paste to solidify within 3-5 min after mixing. However, for the industrial production of cement particle boards, a minimum open time, i.e. the time from adding the water to the binder to the initial setting, of about half an hour is required, to allow blending and mat forming. Thus, ammonium carbonate and sodium carbonate are not. suitable as accelerators, because an undesirable pre-setting of the inorganic binder will occur. The addition of potassium carbonate gives a longer open time. 
A further prolongation is achieved by the addition of waterglass to such a solution. Increasing temperatures shorten the setting time of a mixture of cement, potassium carbonate and waterglass solution, as is demonstrated in Fig. 10.

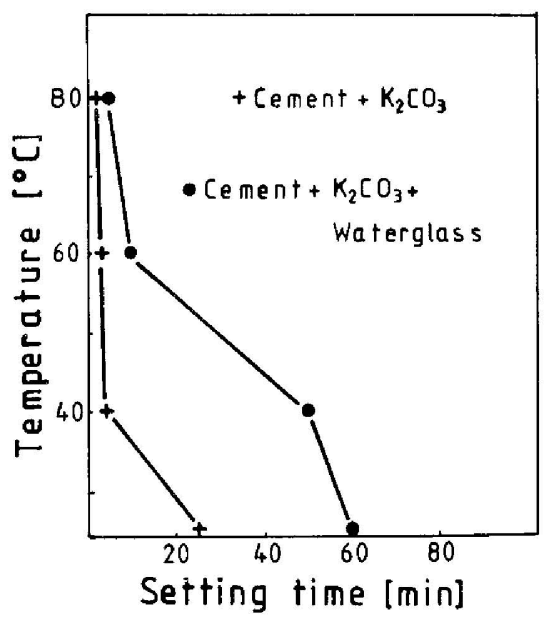

Fig. 10. Setting time of cement paste with the addition of $13.5 \%$ of $\mathrm{K}_{2} \mathrm{CO}_{3}$ and $1.5 \%$ of waterglass monitored by measuring the hydration temperatures.

\subsection{Properties of cement particle boards}

The fabrication of cement particle boards with satisfactory properties at a carbon dioxide pressure of 1-3 bar was not feasible (Table 4). Boards pressed at a carbon dioxide pressure of 5 bar show a somewhat higher bending strength than those fabricated at 7 or 9 bar. However, the distribution of carbon dioxide at 5 bar is unsatisfactory, thus, in subsequent examinations a pressure of 7 bar was used. Table 5 lists the properties of cement particle boards made by the conventional method, addition to carbonate or injection of carbon dioxide using spruce or larch wood particles. Larch wood particles were not suitable to fabricate cement particle boards by conventional methods. However, the addition of carbonates as well as the injection of carbon dioxide resulted in boards with satisfactory properties.

\section{DISCUSSION OF THE RESULTS}

The addition of sodium or potassium carbonate to enhance the setting of portland cement

Table 4. Properties of cement particle boards fabricated at various carbon dioxide pressures

\begin{tabular}{|c|c|c|c|c|}
\hline $\begin{array}{c}\text { Carbon dioxide } \\
\text { pressure } \\
\text { (bar) }\end{array}$ & $\begin{array}{c}\text { Maximum hydration } \\
\text { temperature } \\
\left({ }^{\circ} \mathrm{C}\right)\end{array}$ & $\begin{array}{c}\text { Total hydration } \\
\text { time } \\
(\mathrm{min})\end{array}$ & $\begin{array}{c}\text { Density } \\
\left(\mathrm{kg} \mathrm{m}^{-3}\right)\end{array}$ & $\begin{array}{c}\text { Bending strength } \\
(\mathrm{MPa})\end{array}$ \\
\hline $1 \cdot 5$ & $61 \cdot 0$ & $2 \cdot 6$ & $-^{+}$ & - \\
\hline 3 & 66.6 & 1.8 & $-^{\dagger}$ & - \\
\hline 5 & $67 \cdot 1$ & $1 \cdot 2$ & 1130 & $13 \cdot 8$ \\
\hline 7 & 88.4 & $1 \cdot 2$ & 1130 & $12 \cdot 5$ \\
\hline 9 & $102 \cdot 4$ & $1 \cdot 1$ & 1140 & $12 \cdot 6$ \\
\hline
\end{tabular}

${ }^{\dagger}$ Unsatisfactory board.

Table 5. Properties of cement particle boards fabricated by various methods

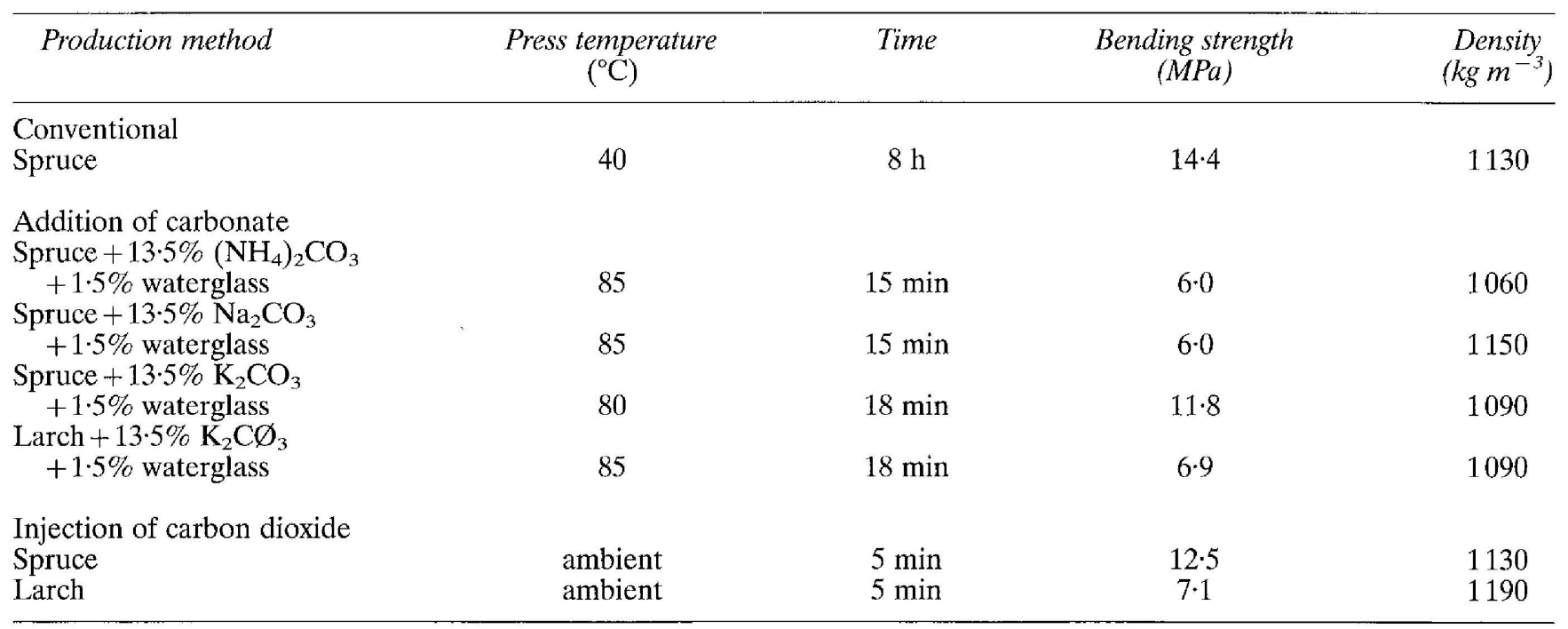


paste, e.g. in shotcrete, is widely used in concrete technology. The treatment of cementbonded composites with carbon dioxide enriched gases to accelerate the solidification of cement paste has been reported by many authors. A review of the technical processes is described in the patent of Malinowski ${ }^{7}$ and in the presentation of Simatupang et al. ${ }^{5}$ In older patents the described carbonations are accomplished either at atmospheric pressure or in autoclaves at higher pressures. In some processes a vacuum is applied before introducing carbon dioxide in order to displace air and to ensure a proper distribution of the carbon dioxide. Most of the processes described in the patent literature propose the application of waste gases enriched with carbon dioxide which are applied at ambient temperatures. Since carbonation is an exothermic reaction, the temperature of the composite will rise and enhance the hydration of the clinker phase. Simunic $^{8}$ proposes an alternating heating and cooling of the cement-bonded composites with the intention of enhancing the evaporation of moisture and the absorption of carbon dioxide. However, the reported solidification times of around $4 \mathrm{~h}$ are relatively long. Carbonation is a rapid reaction, as was shown by the spark plug method. Calcium hydroxide on the surface of the cement paste is carbonated within seconds (Fig. 6), whereas that in the inside, which is less accessible, reacts within a few minutes. A higher carbon dioxide pressure reduces the setting time (Fig. 7). In the following, the solidification times of cement pastes determined by the spark plug method and by the fabrication of both wood/cement specimens and experimental cement particle boards are compared.

Solidification time at a pressure of 7 bar is $2.75 \mathrm{~min}$, wherease the recorded total hydration times during compression of wood/cement specimens and cement particle boards are $1.6 \mathrm{~min}$ and $1.2 \mathrm{~min}$, respectively. Longer solidification times in the spark plug method result from the thicker cement paste layer as compared to the cement paste layer on the wood flakes in cement particle boards, which is about $0 \cdot 1-0 \cdot 2 \mathrm{~mm}$ thick.

It is clearly demonstrated that by direct injection of carbon dioxide into the pressed furnish at 7 bar the solidification of the cement paste can be reduced to less than 2 min. The press cycle, i.e. the time between loading and unload- ing the composite from the hydraulic press, took, in these experiments, 4-5 min, and corresponds well with that in industrial practice.

Freshly carbonated specimens (Table 3 ) contain very small amounts of calcium hydroxide, and this amount does not increase substantially during further hydration for 28 days. The formation of more calcium hydroxide should, however, be expected because unhydrated clinker phases are still available in the pressed specimens.

Bentur $^{9}$ and Gram $^{10}$ applied carbonation to hardened glass fiber and sisal fiber reinforced cement fiber boards with an intention to neutralize the calcium hydroxide and to increase the durability of the composites. The results of Bentur showed that the weakening rate of glass fiber reinforced specimens was retarded by carbonation. Gram observed that sisal fibers on the surfaces of the composites, i.e. those embedded in carbonated concrete, remain intact, whereas those in deeper layers become brittle. Further investigations on the influence of a carbon dioxide injection during formation on the durability of portland cement-bonded lignocellulosic composites are required.

According to Berger et al. ${ }^{11}$ carbon dioxide accelerates the hydration of calcium silicates, and the formed calcium hydroxide is simultaneously carbonated to calcium carbonate. The water/cement ratio is in this process a limiting factor. Klemm and Berger ${ }^{12}$ found in their experiments an optimum water/cement ratio of around $0 \cdot 1$, which is in agreement with results of other authors. ${ }^{13-16}$ The compression strength of carbonated specimens from experiments by Klemm and Berger ${ }^{12}$ did not show any further increase after three days. The reason for this unusual phenomenon was not stated. It is possible that the water required for further hydration of the clinker phase was not available.

In these studies, the optimum water/cement ratio was found to be rather high at $0 \cdot 3$. The reason for this substantial difference -0.3 vs 0.1 by Klemm and Berger ${ }^{12}$ - is caused by the different porosity of the aggregates. Klemm and Berger $^{12}$ used sand, whereas in the experiments we reported here wood particles were applied. Sand is a dense aggregate and, to achieve sufficient permeability for carbon dioxide, the water/cement ratio has to be very low. Wood particles are sufficiently permeable to the gas, as long as the moisture content is not too high. 
With increasing moisture content of the wood particles the carbon dioxide uptake decreased (Table 2).

Another favorable effect may be attributed to the addition of carbon dioxide. Larch wood particles, glucose and tannin up to an amount of $1 \%$ do not inhibit the cement solidification. As set forth by Simatupang ${ }^{17}$ the carbohydrate, and not a degradation product, forms a complex with the soluble compounds of the cement. According to recent examinations of Uritaria, ${ }^{18}$ and also made plausible by Schubert, ${ }^{19}$ the inhibiting effect of saccharose on the setting of cement results from the formation of soluble calcium hydroxide-carbohydrate complexes in the cement pore water. Calcium hydroxide, which is liberated by the hydration of calcium silicates, does not precipitate. This results in the formation of a stable, oversaturated solution and prevents the further hydration of the silicate phases, especially that of $\mathrm{Ca}_{3} \mathrm{Si}$. In the presence of carbon dioxide, the released calcium hydroxide is directly carbonated. The hydration of the clinker phases is enhanced, as was shown by Berger et al. ${ }^{11}$

\section{CONCLUDING REMARKS}

The solidification of cement paste is accelerated by the addition of carbon dioxide, which is either formed in situ from the decomposition of the carbonates of ammonium, sodium or potassium, or injected as a gas. The carbonation is a rapid process in which the calcium hydroxide on the surface of the cement paste reacts within seconds whereas the less accessible material requires a few minutes. The reaction time is reduced by higher carbon dioxide pressures and prolonged by thicker cement paste layers. The gas permeability - indirectly controlled by the water/cement ratio - is a decisive factor for the carbonation rate of the cement paste and the calcium carbonate content of the set wood/ cement composite. Optimum conditions are found at a carbon dioxide pressure of 7 bar and a water/cement ratio of $0 \cdot 3$. The X-ray diffractions confirmed the finding of Berger et al. ${ }^{11}$ that carbon dioxide gas accelerates the hydration of calcium silicates, and directly carbonates the released calcium hydroxide. This is also the reason why larch wood, which is known for inhibiting the hydration of cement, can be used for the fabrication of wood/cement composites if carbon dioxide is present during setting of the inorganic binder.

The press time of cement/wood composites is around $4 \mathrm{~min}$ if carbon dioxide gas is directly injected into the furnish during compression, or around $15 \mathrm{~min}$ if a carbonate of ammonium, sodium or potassium is added to the cement. However, the open time of a cement paste provided with either a solution of ammonium or sodium carbonate is too short to allow an application in the industrial production of cement particle boards.

\section{ACKNOWLEDGEMENTS}

Thanks are due to Dr Sylla, Forschungsinstitut der Zementindustrie, 4000 Düsseldorf, for the $\mathrm{X}$-ray determination, and to the Deutsche Gesellschaft für Holzforschung, 8000 München for financial support.

\section{REFERENCES}

1. Elmendorf, A., Method of making a non-porous board composed of strands of wood and portland cement. US Patent No. 3,271,492. Sept. 6, 1966.

2. Aoki, Y., The manufacture of heat hardening cement particle board. In Inorganic Bonded Wood and Fiber Composite Materials, ed. A. Moslemi, Forest Products Research Society, Wisconsin 53705, 1991.

3. Lahtinen, P. K., Experiences with cement-bonded particle boards manufacturing when using a short-cycle press line (ibid.).

4. Simatupang, M. H., Der Wasserbedarf bei der Herstellung zementgebundener Holzwerkstoffen. Holz Roh-Werkstoff, 37 (1991) 379-82.

5. Simatupang, M. H., Seddig, N., Habighorst, C. \& Geimer, R. L., Technologies for rapid production of mineral-bonded wood composites boards (ibid.).

6. Franke, B., Bestimmung von Calciumoxyd und Calciumhydroxyd neben wasserfreiem und wasserhaltigem Calciumsilikat. Zeitschr. Anorg. Chem. Allg. Chem., 247 (1941) 180-4.

7. Malinowski, R., Method of casting concrete. US Patent No. 4,362,679. Dec. 7, 1982.

8. Simunic, B., Process for accelerating the initial hardening of elements formed of mixture of cement or other lime-containing hydraulic binder and organic or inorganic aggregates therefore. US Patent No. 3,492,385. Jan. 27, 1970.

9. Bentur, A., Durability of carbonated glass fiber reinforced cement composites. Durability of Building Mater., 1 (1983) 313-26.

10. Gram, H.-E., Durability of Natural Fibres in Concrete. Swedish Cement and Concrete Research Institute, S-100 44 Stockholm, p. 99, 1983.

11. Berger, R. L., Young, J. F. \& Leung, K., Acceleration of hydration of calcium silicates by carbon dioxide. Nature Phys. Sci., 240 (1972) 16-18.

12. Klemm, W. A. \& Berger, R. L., Accelerated curing of 
cementitious systems by carbon dioxide. Cement Concrete Res., 2 (1972) 567-76.

13. Zelmanoff, N., Process for the manufacture of artificial stones. US Patent No. 3,149,986. Sept. 22, 1964.

14. Bierlich, K. G., Manufacture of portland cement products. US Patent No. 3,468,993. Sept. 23, 1969.

15. Murray, J. A., Method for the manufacture of concrete and like products. US Patent No. 4,093,690. June 6, 1978.

16. Moorehead, D. R. \& Davis, M., Method of producing a building element. UK Patent No. 2,027,085. 4 Aug. 1978.
17. Simatupang, M. H., Abbaureaktionen von Glucose, Cellobiose und Holz unter Einflub von Portlandzement. Holzforschung, 40 (1986) 149-55.

18. Urrutia, C., Zum Mechanismus der Saccharose auf das Erstarren und Erhärten von Zementen. Diss. Rheinisch-Westfälischen Tech. Hochschule Aachen. Fakultät für Bergbau, Huttenwesen und Geowissenschaften, 1987.

19. Schubert, B., Untersuchungen zum System HolzZement-Wasser. Diss. TU Dresden, Fakultät für Bau-, Wasser- und Forstwesen, 1991. 
